Article

\title{
Synergistically-Enhanced Thermal Conductivity of Shape-Stabilized Phase Change Materials by Expanded Graphite and Carbon Nanotube
}

\author{
Zhang-Peng Liu and Rui Yang * \\ Department of Chemical Engineering, Tsinghua University, Beijing 100084, China; \\ liuzp14@mails.tsinghua.edu.cn \\ * Correspondence: yangr@mail.tsinghua.edu.cn; Tel.: +86-10-6279-7405 \\ Academic Editors: Luisa F. Cabeza and Sumin Kim \\ Received: 2 May 2017; Accepted: 31 May 2017; Published: 2 June 2017
}

Featured Application: This work faces applications in energy-saving buildings. The involved shape-stabilized phase change material is a promising material used in walls or floors of buildings to regulating the room temperature in a comfortable range, taking advantage of clean and sustainable solar energy or off-peak electricity.

\begin{abstract}
The thermal conductivity of expanded graphite plate (EGP) and/or multi-wall carbon nanotube (MWCNT)-filled, shape-stabilized, phase change material (SSPCM), based on paraffin, high-density polyethylene (HDPE), and styrene-butadiene-styrene copolymer (SBS), was investigated. The results demonstrated that both EGP and MWCNT increased the thermal conductivity of the SSPCM. EGP showed a greater thermal conductivity improvement than MWCNT. The conductivity of EGP-filled SSPCM reached $0.574 \mathrm{~W} / \mathrm{mK}$ at $9 \mathrm{wt} \%$, while that of MWCNT was just $0.372 \mathrm{~W} / \mathrm{mK}$ at the same loading. Furthermore a series of EGP/MWCNT hybrid fillers were prepared and introduced into the SSPCM, and a synergistic effect was observed between the two fillers. When the EGP/MWCNT ratio was 8:2, the most significant thermal conductivity enhancement to the SSPCM was obtained. The thermal conductivity was $0.674 \mathrm{~W} / \mathrm{mK}, 288 \%$ that of the SSPCM and $117 \%$ that of $9 \mathrm{wt} \%$ EGP-filled SSPCM. The SEM photos showed that a bridging of two-dimensional (2D) planar EGP by flexible one-dimensional (1D) MWCNT was constructed. The so-formed EGP-MWCNT network favored heat transfer along it and led to a decreased thermal interface resistance due to the increased EGP-MWCNT junctions.
\end{abstract}

Keywords: shape stabilized phase change material (SSPCM); thermal conductivity; expanded graphite plate (EGP); multi-wall carbon nanotube (MWCNT); synergistic effect

\section{Introduction}

Thermal energy storage system, using phase change materials (PCMs) to absorb and release large amounts of heat during the phase change process with reduced temperature fluctuations, is an efficient system to improve energy efficiency and, thus, reduce $\mathrm{CO}_{2}$ emissions [1,2]. PCMs are classified into two major categories: inorganic and organic PCMs. Inorganic PCMs, such as hydrated salts, salts, metals, and alloys, usually have high latent heat, relatively high thermal conductivity and small volume change. However, disadvantages, such as toxicity, corrosion, super-cooling, and phase separation during the phase change process, significantly restrict their practical application. In contrast, organic PCMs, such as paraffins, fatty acids, and alcohols, especially paraffins, have versatile phase change temperatures, high latent heat, and good chemical stability, and are non-toxic with little super-cooling. Therefore, paraffins are the most promising PCMs [3]. 
In spite of these attractive properties, paraffin PCMs suffer from low thermal conductivity $(0.1-0.3 \mathrm{~W} / \mathrm{mK})$, which limits its applications [4]. The general way to improve thermal conductivity of paraffin PCMs is to add highly thermally-conductive fillers. Metal fillers have good thermal conductivity and, thus, were used often [5-9]. For example, Wu et al. [6] reported that by adding $1 \mathrm{wt} \% \mathrm{Cu}$ nanoparticles into paraffin $\left(\mathrm{Tm}=58-60^{\circ} \mathrm{C}\right)$, the heating and cooling times were reduced by $30.3 \%$ and $28.2 \%$, respectively. Xiao et al. [8] prepared paraffin $\left(\mathrm{Tm}=60-62{ }^{\circ} \mathrm{C}\right) /$ nickel foam and paraffin/copper foam composites by using a vacuum impregnation method. The result showed that the thermal conductivities of the paraffin/nickel foam and the paraffin/copper foam composites were nearly three and 15 times larger than that of pure paraffin. Metal oxide fillers have also been used to improve the thermal conductivity of paraffin PCMs, but the enhancement is not significant [10-13]. For example, Wang et al. [10] dispersed $\mathrm{Al}_{2} \mathrm{O}_{3}$ nanoparticles with mass fractions of $1-5 \mathrm{wt} \%$ into paraffin $\left(\mathrm{Tm}=52-56^{\circ} \mathrm{C}\right)$ to prepare the composites. The results revealed that the thermal conductivity of the composite with $5 \mathrm{wt} \% \mathrm{Al}_{2} \mathrm{O}_{3}$ was higher than pure paraffin by about $0.07 \mathrm{~W} / \mathrm{mK}$ in the solid state at $288 \mathrm{~K}$, and $0.05 \mathrm{~W} / \mathrm{mK}$ in the liquid state at $338 \mathrm{~K}$, respectively. Jesumathy et al. [12] added $40 \mathrm{~nm} \mathrm{CuO}$ particles into paraffin $\left(\mathrm{Tm}=58{ }^{\circ} \mathrm{C}\right)$. The thermal conductivity was enhanced $6-7.8 \%$ in the liquid state, and the heat transfer coefficient during solidification was increased by about $78 \%$ for the maximum flow rate.

Although metals and metal oxides have enhanced the thermal conductivity of PCMs, they obviously increased the weight of the PCMs, and decreased the heat storage density and the thermal and chemical stability [14]. In recent years, carbon based fillers, such as graphite, carbon nanofibers, carbon nanotubes, and graphene, were used to enhance the thermal conductivity of PCMs because of their excellent thermal conductivity and low density [15-27]. For example, Shi et al. [15] prepared PCMs by mixing paraffin $\left(\mathrm{Tm}=61.6^{\circ} \mathrm{C}\right)$ with exfoliated graphite nanoplatelets $(\mathrm{xGnP})$ or graphene in hot toluene, followed by solvent evaporation and vacuum drying. The result revealed that the solid-phase thermal conductivities of paraffin/ $\mathrm{xGnP}$ and paraffin/graphene composites were $2.7 \mathrm{~W} / \mathrm{mK}$ and $0.5 \mathrm{~W} / \mathrm{mK}$, respectively, significantly higher than that of pure paraffin $(0.25 \mathrm{~W} / \mathrm{mK})$. Xia et al. [19] prepared PCMs by mixing paraffin $\left(\mathrm{Tm}=50-55{ }^{\circ} \mathrm{C}\right)$ with expanded graphite (EG). The result revealed that the heat storage/retrieval durations for EG(10)/paraffin(90) composite were reduced by $48.9 \%$ and $66.5 \%$, respectively. Wang et al. [23] dispersed multi-wall carbon nanotubes (MWCNTs) in paraffin $\left(\mathrm{Tm}=52-54{ }^{\circ} \mathrm{C}\right)$. The result revealed that the thermal conductivity of paraffin with $2 \mathrm{wt} \%$ MWCNTs was enhanced $35.0 \%$ and $45.0 \%$ in solid and liquid states. Mohammad et al. [25] prepared a PCM composite by vacuum impregnation of paraffin $\left(\mathrm{Tm}=50-60^{\circ} \mathrm{C}\right)$ with graphene oxide $(\mathrm{GO})$ sheets. The result revealed that the thermal conductivity of the composite was improved from 0.305 to $0.985 \mathrm{~W} / \mathrm{mK}$.

Although high thermal conductivity was easily achieved by incorporating paraffin with thermal conductive fillers, the composites have no mechanical strength, and leakage of paraffin during storage, transportation, and usage is a significant problem. Shape-stabilized phase change material (SSPCM) with a polymer matrix as supporting and encapsulation materials [28-30] is a good solution for strength and leakage. However, only a few works on thermal conductivity enhancement of SSPCM have been found in the literature [31-35]. For example, Xiao et al. [34] found that expanded graphite in styrene-butadiene-styrene copolymer (SBS)/paraffin composite helped to decrease the heat release time by $61 \%$. Cheng et al. [33] found that EG enhanced the thermal conductivity of an HDPE/paraffin composite more than graphite powder (GP). Patrix et al. [32] used linear low-density polyethylene, paraffin wax, and expanded graphite (EG) to prepare SSPCM. They found that the thermal conductivity was increased to $1.329 \mathrm{~W} / \mathrm{mK}$ for SSPCM containing $15 \mathrm{wt} \%$ of EG.

Although many works have been carried out and the thermal conductivity of paraffin was improved to different extents, relative works on thermal conductivity enhancement of paraffin-based SSPCM are not sufficient. Most of the previous works focused on preparation and thermal property determination, with little discussion on thermal conductivity enhancement mechanisms and the effect of filler(s) dispersion morphology in SSPCM. In addition, most of works were based on paraffins 
with a high phase change temperature $\left(50-60{ }^{\circ} \mathrm{C}\right)$; paraffins with phase change temperatures of $20-30{ }^{\circ} \mathrm{C}$, which are required for energy-saving buildings, are not concerned. Therefore, in this paper, a two-dimensional (2D) structure filler-expanded graphite plate (EGP) and a one-dimensional (1D) structure filler-multi-wall carbon nanotube (MWCNT) were used to enhance the thermal conductivity of the SSPCM, which was prepared for building applications with good comprehensive properties [29]. The effect of filler dispersion morphology on thermal conductivity was investigated. Furthermore, a synergistic effect between EGP and MWCNT fillers were observed, and the synergistic mechanism was discussed.

\section{Experimental}

\subsection{Materials}

Paraffin, (melting temperature: $20-25^{\circ} \mathrm{C}$; latent heat: $122.6 \mathrm{~J} / \mathrm{g}$ ), was from the Shijiazhuang Zhongdejieneng Phase Change Materials Company, Shijiazhuang, China. High-density polyethylene (HDPE) was provided by Beijing Eastern Petrochemical Co., Ltd. (Beijing, China). SBS (linear copolymer, $\mathrm{S} / \mathrm{B}=3 / 7$ ) was obtained from Dushanzi Petrochemical Co., Ltd., Karamay, China. Expandable graphite (expansion ratio 100-400 mL/g) was supplied by Qingdao Jinrilai Co., Ltd., Qingdao, China. Raw multi-wall carbon nanotubes (MWCNTs), with a statistical diameter of $10 \mathrm{~nm}$ and a statistical length of $10 \mu \mathrm{m}$, were supplied by the Department of Chemical Engineering, Tsinghua University, China. The thermo-physical properties of these materials are listed in Table 1.

Table 1. The thermo-physical properties of the materials.

\begin{tabular}{ccccc}
\hline Materials & $\begin{array}{c}\text { Density } \\
\left(\mathbf{g} / \mathbf{c m}^{3}\right)\end{array}$ & $\begin{array}{c}\text { Thermal Conductivity } \\
\mathbf{( W / m K )}\end{array}$ & $\begin{array}{c}\text { Specific Heat } \\
\mathbf{( J / g K )}\end{array}$ & $\begin{array}{c}\text { Melting Point } \\
{ }^{\circ} \mathbf{C}\end{array}$ \\
\hline HDPE & $0.94 \sim 0.96$ & 0.44 & 2.3 & 130 \\
SBS & $0.92 \sim 0.95$ & 0.16 & 1.9 & - \\
Paraffin & 0.915 & 0.14 & 2.5 & $20-25$ \\
EGP [20] & 1.8 & 100 & 0.71 & - \\
WMCNT [36,37] $^{*}$ & 1.8 & $200 / 3000$ & 0.71 & - \\
\hline
\end{tabular}

* The thermal conductivity of a single MWCNT is over $3000 \mathrm{~W} / \mathrm{mK}$ [37], while the value of a MWCNT film in the nanotube axis direction is about $200 \mathrm{~W} / \mathrm{mK}$ [36].

\subsection{Treatment of Expandable Graphite and MWCNT}

Expandable graphite was first held in a muffle furnace (Shenyang Energy Saving Furnace Company, Shenyang, China) at $900{ }^{\circ} \mathrm{C}$ for $30 \mathrm{~s}$ to form expanded graphite (EG). Then, EG was sheared in hexane at 20,000 r/min for $30 \mathrm{~min}$ by a homogenizer (FM200, Fluko Equipment Shanghai Co., Ltd, Shanghai, China), followed by bath sonication for $1 \mathrm{~h}$ to obtain expanded graphite plate (EGP).

MWCNTs were sheared in hexane at 20,000 r/min for $30 \mathrm{~min}$, followed by bath sonication for $1 \mathrm{~h}$.

\subsection{Preparation of Hybrid Fillers}

Several grams of EGP and MWCNT were dispersed in $1000 \mathrm{~mL}$ hexane by shearing at 20,000 r/min for $30 \mathrm{~min}$, followed by bath sonication for $1 \mathrm{~h}$ to obtain hybrid fillers named as $\mathrm{EGP}_{\mathrm{x}}-\mathrm{MWCNT}_{10-\mathrm{x}}$ (x EGP with a total loading of 10 fillers).

\subsection{Preparation of Thermal Conductivity Enhanced SSPCMs}

EGP (1-12 wt \%), MWCNT (1-10 wt \%), or EGP -MWCNT $_{10-x}(10 \mathrm{wt} \%)$, was mixed with SBS, HDPE, and paraffin (with a mass ratio of 30/10/60). Next, the mixture was melt-blended at $140{ }^{\circ} \mathrm{C}$ for $10 \mathrm{~min}$ in a torque rheometer (RM-200A Rheometer, Harbin Hapro Electrical Technology Co., Harbin, China) at $60 \mathrm{rpm}$. Then, it was hot-pressed at $140{ }^{\circ} \mathrm{C}$ into disks for thermal conductivity determination. The compositions of the SSPCMs (shape-stabilized phase change material) are listed in Table 2. 
Table 2. The compositions of thermal conductivity-enhanced SSPCMs (shape-stabilized phase change material).

\begin{tabular}{|c|c|c|c|}
\hline Sample & Composition (Mass Ratio) & Filler Content/(wt \%) & Density $/\left(\times 10^{3} \mathrm{~kg} / \mathrm{m}^{3}\right)$ \\
\hline PCM & SBS $/ H D P E /$ paraffin $=30 / 10 / 60$ & 0 & 0.800 \\
\hline PCM-1EGP & $\mathrm{PCM} / \mathrm{EGP}=100 / 1$ & 0.99 & 0.800 \\
\hline PCM-3EGP & $\mathrm{PCM} / \mathrm{EGP}=100 / 3$ & 2.91 & 0.810 \\
\hline PCM-5EGP & $\mathrm{PCM} / \mathrm{EGP}=100 / 5$ & 4.76 & 0.822 \\
\hline PCM-7EGP & $\mathrm{PCM} / \mathrm{EGP}=100 / 7$ & 6.54 & 0.834 \\
\hline PCM-10EGP & $\mathrm{PCM} / \mathrm{EGP}=100 / 10$ & 9.09 & 0.849 \\
\hline PCM-12EGP & $\mathrm{PCM} / \mathrm{EGP}=100 / 12$ & 10.71 & 0.858 \\
\hline PCM-1MWCNT & $\mathrm{PCM} / \mathrm{MWCNT}=100 / 1$ & 0.99 & 0.807 \\
\hline PCM-3MWCNT & $\mathrm{PCM} / \mathrm{MWCNT}=100 / 3$ & 2.91 & 0.824 \\
\hline PCM-5MWCNT & $\mathrm{PCM} / \mathrm{MWCNT}=100 / 5$ & 4.76 & 0.832 \\
\hline PCM-7MWCNT & $\mathrm{PCM} / \mathrm{MWCNT}=100 / 7$ & 6.54 & 0.859 \\
\hline PCM-10MWCNT & $\mathrm{PCM} / \mathrm{MWCNT}=100 / 10$ & 9.09 & 0.870 \\
\hline $\mathrm{PCM}-\mathrm{EGP}_{9} \mathrm{MWCNT}_{1}$ & $\mathrm{PCM} / \mathrm{EGP} / \mathrm{MWCNT}=100 / 9 / 1$ & 9.09 & 0.855 \\
\hline 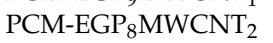 & $\mathrm{PCM} / \mathrm{EGP} / \mathrm{MWCNT}=100 / 8 / 2$ & 9.09 & 0.866 \\
\hline $\mathrm{PCM}-\mathrm{EGP}_{7} \mathrm{MWCNT}_{3}$ & $\mathrm{PCM} / \mathrm{EGP} / \mathrm{MWCNT}=100 / 7 / 3$ & 9.09 & 0.867 \\
\hline $\mathrm{PCM}^{-E P_{5} \mathrm{MWCNT}_{5}}$ & $\mathrm{PCM} / \mathrm{EGP} / \mathrm{MWCNT}=100 / 5 / 5$ & 9.09 & 0.860 \\
\hline 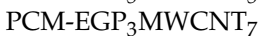 & $\mathrm{PCM} / \mathrm{EGP} / \mathrm{MWCNT}=100 / 3 / 7$ & 9.09 & 0.861 \\
\hline
\end{tabular}

\subsection{Characterization}

\subsubsection{Scanning Electron Microscopy}

The morphologies of fillers and SSPCMs were observed by a field emission scanning electron microscope (FESEM, JSM-6700F (JEOL Ltd.), Tokyo, Japan) at an accelerating voltage of $5 \mathrm{kV}$.

\subsubsection{Differential Scanning Calorimetry (DSC)}

The melting and crystallization temperature of a sample was determined by differential scanning calorimetry (DSC) (Q-100, TA Instrument, New Castle, DE, USA) in a temperature range of $-30{ }^{\circ} \mathrm{C} \sim 50{ }^{\circ} \mathrm{C}$ at $10{ }^{\circ} \mathrm{C} / \mathrm{min}$. The specific heat $\left(C_{p}, \mathrm{~J} / \mathrm{gK}\right.$, measurement accuracy is $\left.0.01 \mathrm{~J} / \mathrm{gK}\right)$ was determined at $35^{\circ} \mathrm{C}$ by DSC (Q-100, TA Instrument, Whatcom, WA, USA), and the values are shown in Table 3.

Table 3. The specific heat values of the compositions of thermal conductivity-enhanced SSPCMs.

\begin{tabular}{cc}
\hline Sample & $C_{p} /(\mathrm{J} / \mathrm{gK})$ \\
\hline PCM & $2.42 \pm 0.19$ \\
PCM-1EGP & $2.38 \pm 0.15$ \\
PCM-3EGP & $2.22 \pm 0.14$ \\
PCM-5EGP & $2.23 \pm 0.10$ \\
PCM-7EGP & $2.28 \pm 0.13$ \\
PCM-10EGP & $2.35 \pm 0.17$ \\
PCM-12EGP & $2.34 \pm 0.17$ \\
PCM-1MWCNT & $2.33 \pm 0.11$ \\
PCM-3MWCNT & $2.31 \pm 0.10$ \\
PCM-5MWCNT & $2.37 \pm 0.15$ \\
PCM-7MWCNT & $2.31 \pm 0.14$ \\
PCM-10MWCNT & $2.34 \pm 0.12$ \\
PCM-EGP 9 MWCNT & $2.31 \pm 0.16$ \\
PCM-EGP $_{8}$ MWCNT & $2.30 \pm 0.15$ \\
PCM-EGP $_{7}$ MWCNT & $2.27 \pm 0.14$ \\
PCM-EGP $_{5}$ MWCNT $_{5}$ & $2.32 \pm 0.11$ \\
PCM-EGP $_{3}$ MWCNT $_{7}$ & $2.36 \pm 0.17$ \\
\hline
\end{tabular}

\subsubsection{Thermal Conductivity Test}

Thermal conductivity $(\lambda, \mathrm{W} / \mathrm{mK})$ was calculated according to equation: $\lambda=\alpha \times C_{p} \times \rho$. Thermal diffusivity $\left(\alpha, \mathrm{mm}^{2} / \mathrm{s}\right.$, measurement accuracy is $\left.0.001 \mathrm{~mm}^{2} / \mathrm{s}\right)$ of sample disks $\left(\varnothing 12.7 \times 2 \mathrm{~mm}^{3}\right)$ at $35{ }^{\circ} \mathrm{C}$ was measured by the laser flash method (LFA 447, NETZSCH Instruments Co., Shanghai, 
China). Density $\left(\rho, \mathrm{g} / \mathrm{cm}^{3}\right)$ was calculated by the mass (measurement accuracy is $0.0001 \mathrm{~g}$ ) /volume of samples, as shown in Table 2.

\section{Results and Discussions}

\subsection{Morphology of Fillers}

In order to enhance the thermal conductivity of the SSPCM, a heat transfer network constructed by fillers is required. This demands a good dispersion of fillers in the SSPCM. EG particles have a worm-like structure with nano-platelets adhered to each other (Figure 1a), with size of hundreds of microns. Due to the high surface energy of MWCNTs, they tend to entangle together (Figure 1c), thus strong shearing is required to disentangle or exfoliate them and realize good dispersion. When fillers are melt-blended with low viscosity SSPCM, the shear force is relatively small, so it is difficult to overcome the interaction between fillers just by melt blending, even at high mixing speeds, and the fillers cannot be dispersed evenly in the SSPCM matrix. Therefore, the pretreatment of fillers is necessary to weaken their interaction and lessen the aggregation.
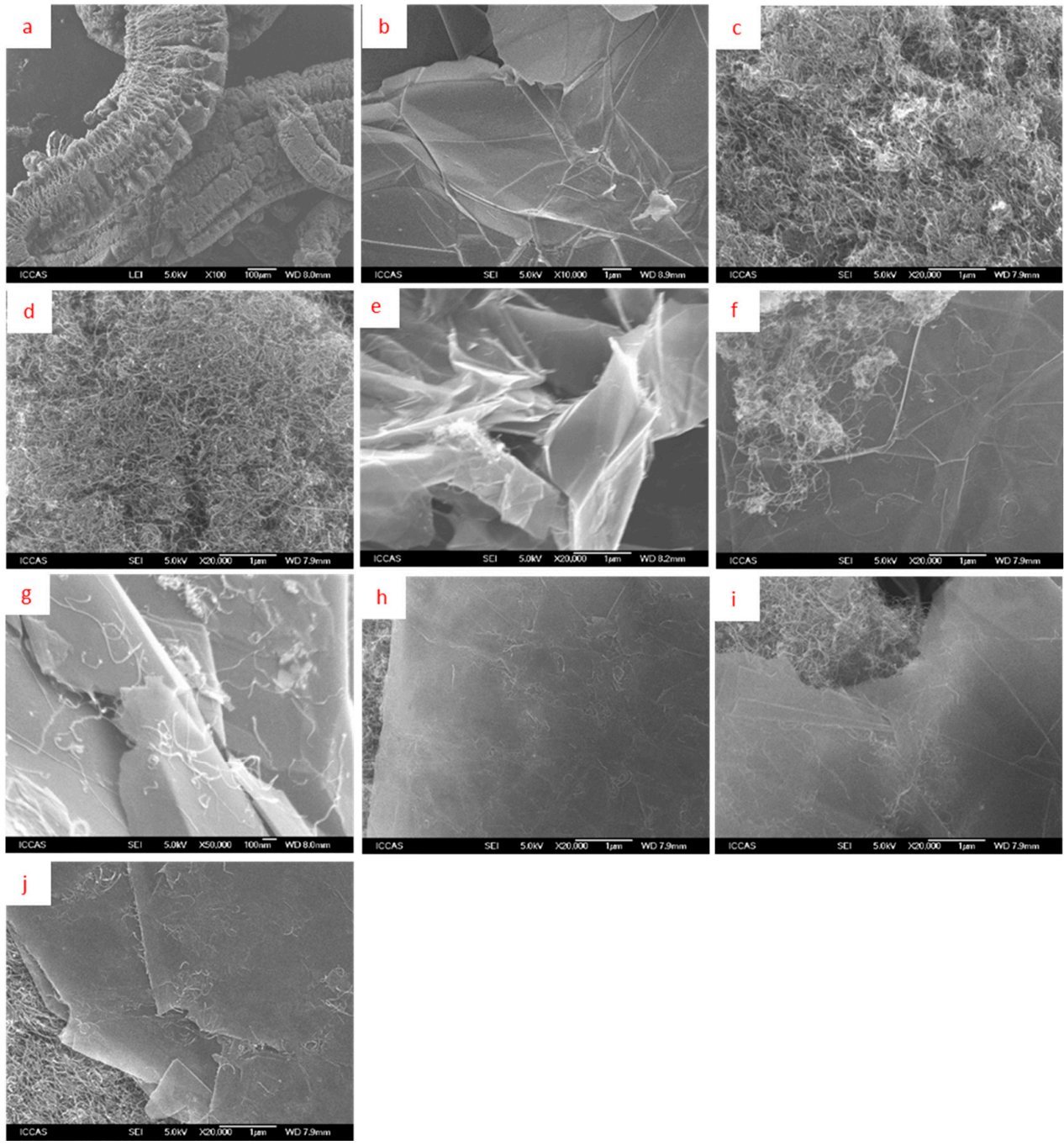

Figure 1. SEM images of (a) EG $(100 \times)$; (b) EGP $(1000 \times)$; (c) MWCNT $(20,000 \times)$; (d) treated MWCNT $(20,000 \times) ;\left(\right.$ e) $\mathrm{EGP}_{9}-\mathrm{MWCNT}_{1}(20,000 \times) ;\left(\right.$ f) $\mathrm{EGP}_{8}-\mathrm{MWCNT}_{2}(20,000 \times)$ and (g) EGP $\mathrm{ESWCNT}_{2}$ (50,000×); (h) $\mathrm{EGP}_{7}-\mathrm{MWCNT}_{3}(20,000 \times)$; (i) $\mathrm{EGP}_{5}-\mathrm{MWCNT}_{5}(20,000 \times)$; and (j) $\mathrm{EGP}_{3}-\mathrm{MWCNT}_{7}$ $(20,000 \times)$. 
Figure 1 shows the morphologies of two fillers and their hybrid after pretreatment by shear and sonication. As shown in Figure 1a, expandable graphite was treated at $900{ }^{\circ} \mathrm{C}$ for $30 \mathrm{~s}$ to obtain expanded graphite (EG) with a worm-like structure, and its volume was expanded hundreds of times. After high-speed shear and sonication, the multi-layer in the worm-like structure was exfoliated to form EGP, as show in Figure 1b. In Figure 1c, primary MWCNT was severely aggregated. After high-speed shear and sonication, MWCNTs became even and loose, as shown in Figure 1d. Figure 1e-j are micrographs of hybrid fillers with different EGP/MWCNT ratios. MWCNTs were adhered on the surface of EGPs. This special bridging structure would benefit the heat transfer between EGPs and MWCNTs and decrease the interface thermal resistance. However, with the increase of MWCNT content in the $\mathrm{EGP}_{\mathrm{x}}-\mathrm{MWCNT}_{10-\mathrm{x}}$ hybrid filler, more MWCNTs were aggregated, rather than adhered on EGPs. For example, in $\mathrm{EGP}_{8}-\mathrm{MWCNT}_{2}$, we can observe more MWCNTs on EGPs than that in $\mathrm{EGP}_{3}-\mathrm{MWCNT}_{7}$.

\subsection{Thermal Conductivity}

The cooling and the heating DSC curves of the SSPCM (as a typical PCM example) are shown in Figure 2. From 0 to $30^{\circ} \mathrm{C}$, the SSPCM underwent a solid-liquid phase change, and the specific heat changed with temperature. Therefore, the thermal conductivity test of the SSPCM has to be carried out in a stable state at a temperature above $35^{\circ} \mathrm{C}$.

a

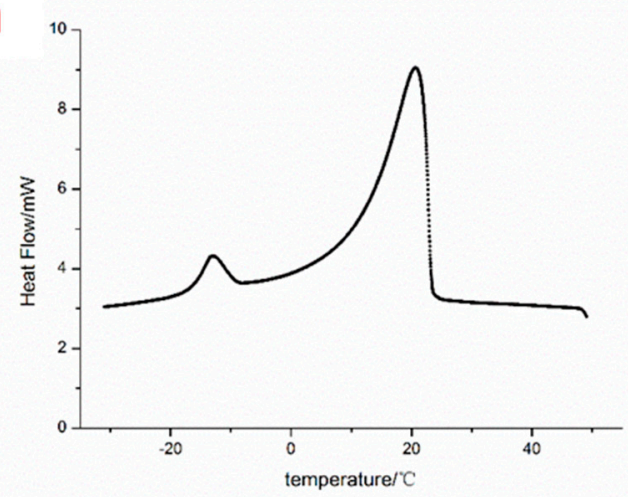

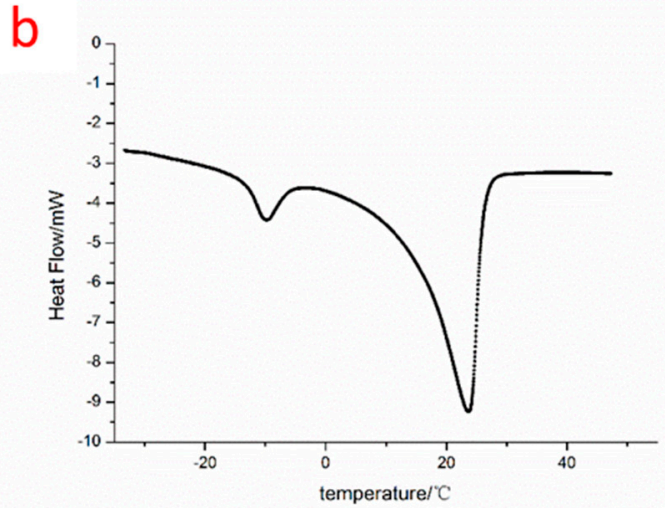

Figure 2. The cooling and the heating DSC curves of PCM: (a) cooling; and (b) heating.

Figure 3 shows the thermal conductivity of SSPCM filled with EGP, MWCNT, and hybrid filler. When a single filler was added, as show in Figure 3a, the thermal conductivity of SSPCM increased with the increasing EGP or MWCNT content. The thermal conductivity of PCM-xEGP composite increased greater than that of PCM-xMWCNT composite. At $9.09 \mathrm{wt} \%$, the thermal conductivity of PCM-10EGP is $0.575 \mathrm{~W} / \mathrm{mK}$, about $246 \%$ that of the SSPCM $(0.234 \mathrm{~W} / \mathrm{mK})$. The thermal conductivity of PCM-10MWCNT is $0.372 \mathrm{~W} / \mathrm{mK}$, about $159 \%$ that of the SSPCM. Therefore, EGP is more effective than MWCNT when serving as the thermally-conductive filler in SSPCM.

MWCNT is a 1D flexible filler with high thermal conductivity and high aspect ratio. EGP is a $2 \mathrm{D}$ rigid filler also with high thermal conductivity and a high aspect ratio. When MWCNT and EGP were pretreated together and added into the SSPCM (total loading is $9.09 \mathrm{wt} \%$ ), a synergistic effect was obtained, as shown in Figure 3b. The dashed line showed the calculated data from the addition law. When EGP content was more than $4.76 \mathrm{wt} \%$, the measured data exceeded the theoretical value, demonstrating the existence of a synergistic effect. The greatest synergistic effect was obtained for PCM-EGP ${ }_{8} \mathrm{MWCNT}_{2}$, with thermal conductivity of $0.674 \mathrm{~W} / \mathrm{mK}$. 


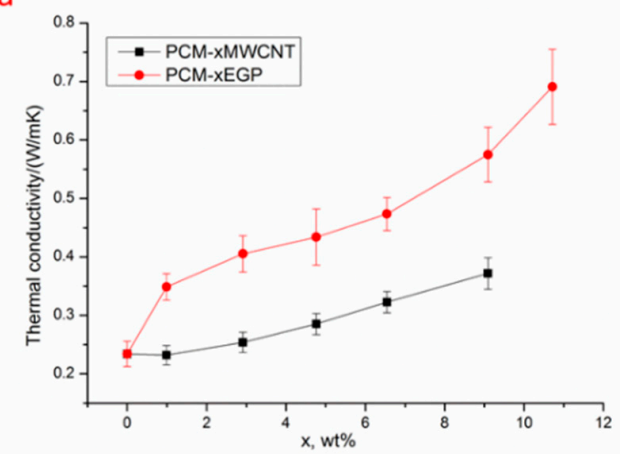

b

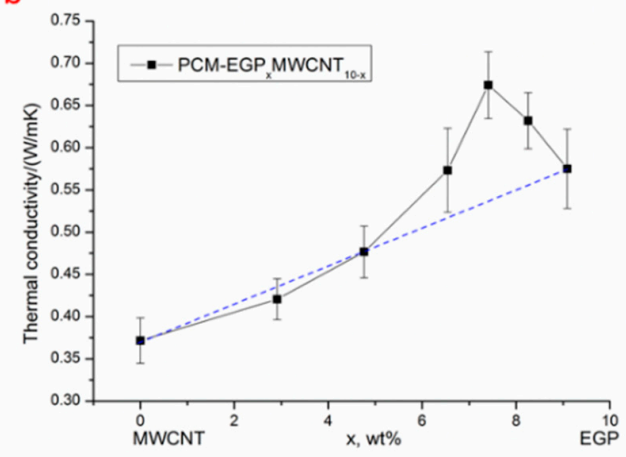

Figure 3. Thermal conductivities (at $35^{\circ} \mathrm{C}$ ) of SSPCM filled with (a) single filler and (b) hybrid filler.

In order to explore whether PCM-EGP $\mathrm{MWCNT}_{2}$ had higher thermal conductivity than PCM-10EGP and PCM-10MWCNT at different temperatures, thermal conductivities at 35, 40, 45, and $50{ }^{\circ} \mathrm{C}$ were determined and are shown in Figure 4. It can be clearly seen that the thermal conductivity of PCM-EGP ${ }_{8} \mathrm{MWCNT}_{2}$ was higher than that of PCM-10EGP and PCM-10MWCNT at different temperatures, demonstrating synergistic enhancement between EGP and MWCNT at all temperatures. In the $35-50{ }^{\circ} \mathrm{C}$ temperature range, the thermal conductivity remained constant. This is because the SSPCM was in a stable state from 35 to $50^{\circ} \mathrm{C}$.

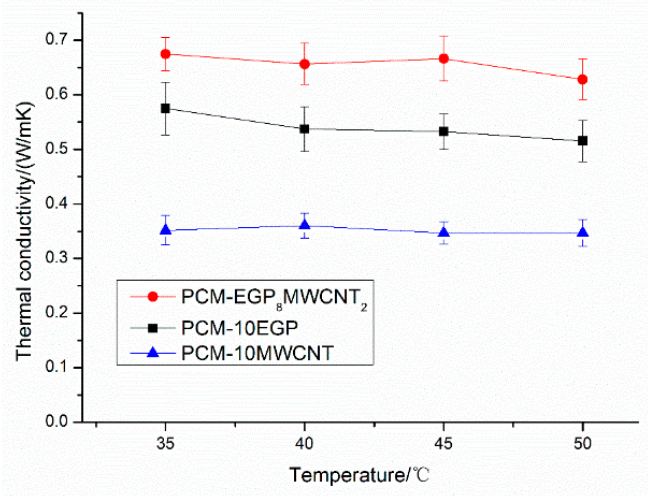

Figure 4. Thermal conductivities of samples at different temperatures.

Meanwhile, the melting or crystallization temperature of SSPCMs filled with EGP or MWCNT were not changed, as shown in Figure 5, demonstrating that the SSPCM and fillers were physically mixed and no strong interaction occurred between them.
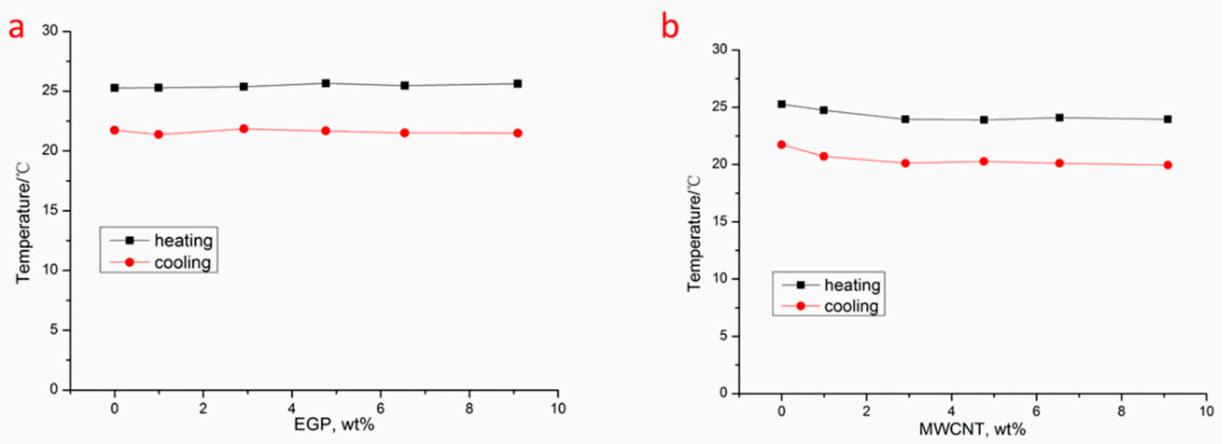

Figure 5. Melting and crystallization temperatures of SSPCM filled with different concentrations of (a) EGP or (b) MWCNT. 


\subsection{Synergistic Mechanism}

Figure 1 demonstrates the formation of bridging structure between linear flexible MWCNT and thin platelet EGP in hybrid fillers, and Figure 3b shows synergistic effect when EGP content was more than $4.54 \mathrm{wt} \%$. In order to reveal the synergistic mechanism, microscopic morphologies of SSPCM filled with 9.09 wt \% EGP, 9.09 wt \% MWCNT, and 9.09 wt \% hybrid fillers, i.e., EGP $\mathrm{BWCNT}_{2}$, $\mathrm{EGP}_{5} \mathrm{MWCNT}_{5}$, and $\mathrm{EGP}_{3} \mathrm{MWCNT}_{7}$, were compared in Figures 6-8. For clarity, paraffin on sectional surface was removed by alcohol before observation. In PCM-10EGP, EGPs were embedded in the SSPCM matrix. Some EGPs contacted each other to form thermally-conductive channels (shown in Figure $6 \mathrm{~b}$, red lines show the EGP edges, and EGPs are partly stacked), which helped to improve the thermal conductivity of SSPCM. However, there were still some aggregated EGPs, which were separated by SSPCM and would not contribute to thermal conductivity enhancement (shown in Figure 6a). In PCM-10MWCNT, a large amount of MWCNT aggregated and was separated by the SSPCM matrix (Figure 7). Thermally-conductive channels or network were not constructed, that is why $9.09 \mathrm{wt} \%$ MWCNT did not improve the thermal conductivity of SSPCM greatly.
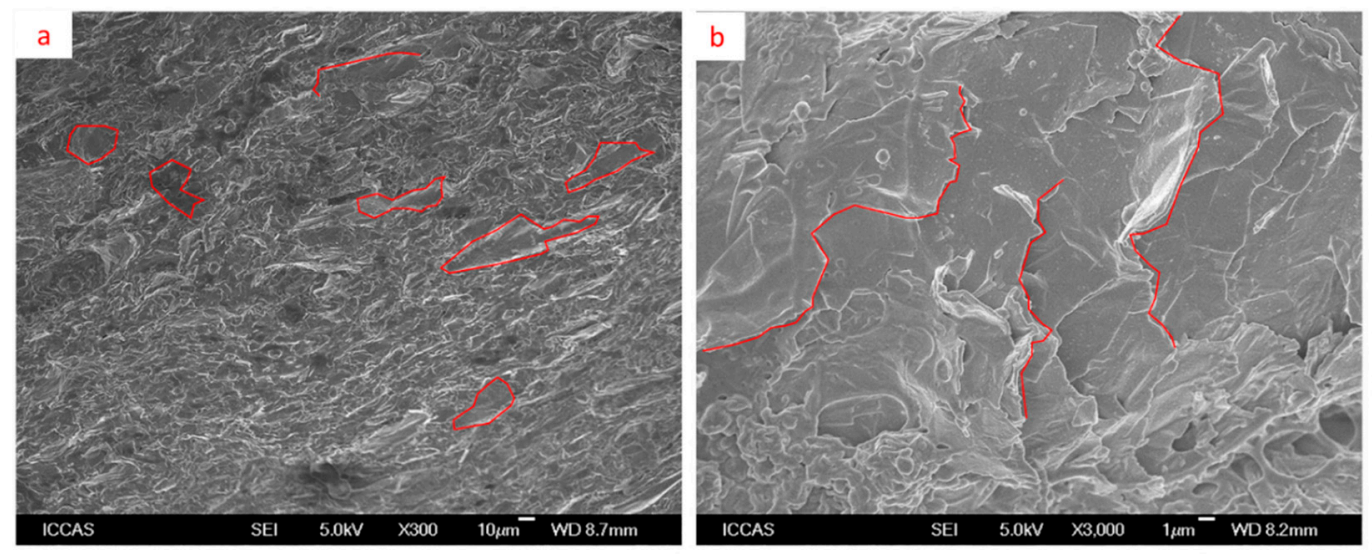

Figure 6. SEM photographs of PCM-10EGP. (a) $(300 \times)$, (b) $(3000 \times)$. The red lines show outlines of some EGPs in the matrix.
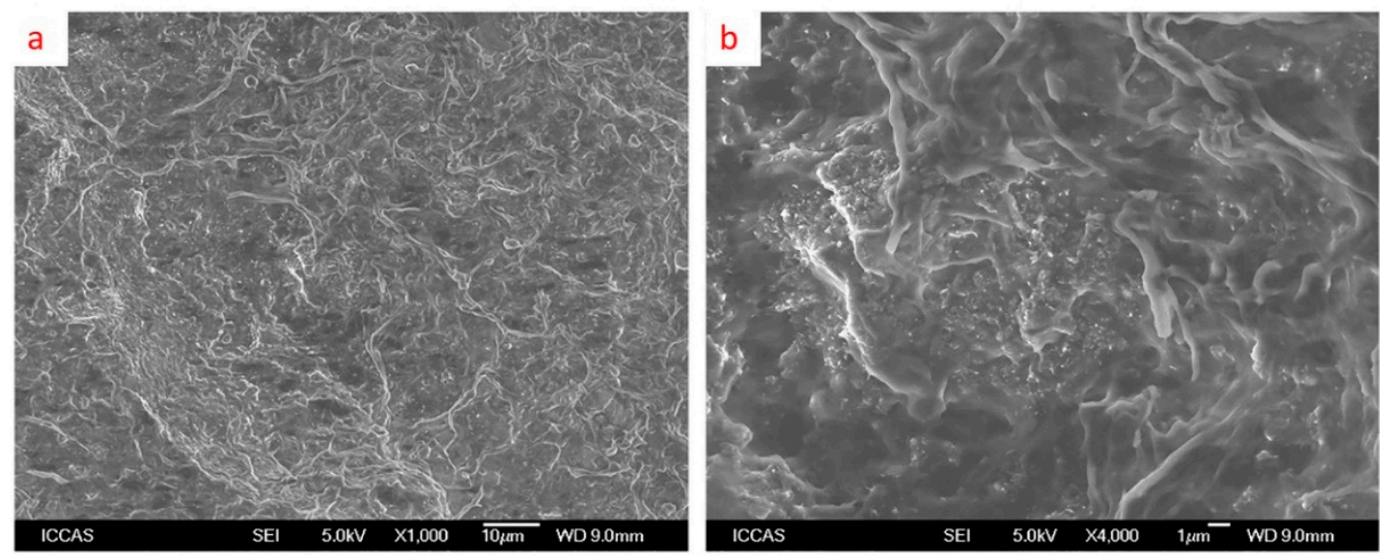

Figure 7. SEM photographs of PCM-10MWCNT: (a) $(1000 \times)$, and (b) $(4000 \times)$.

In SSPCM filled with hybrid fillers, strong interaction between EGPs and MWCNTs helped the bridging between them and, thus, the thermally-conductive network was constructed to achieve a significant improvement of the thermal conductivity. In PCM-EGP ${ }_{8} \mathrm{MWCNT}_{2}, \mathrm{EGPs}$ were evenly dispersed in the SSPCM matrix, and MWCNTs were roughly mono-dispersed in SSPCM 
(in Figure 8(a1,a2)). This morphology favored the formation of heat flow network and benefit thermal transport through the whole sample. Many MWCNTs were adhered to the surface or edge of EGPs (in Figure 8(a3)), bridging EGPs and the SSPCM matrix. This complex nanostructure enhanced the EGP-SSPCM interaction. Thus, phonons transported across the EGP-SSPCM interface easily, which decreased the interface thermal resistance. When the content of EGP was decreased (especially with EGP/MWCNT less than 5:5), it was so low that the distance between EGPs were too far for phonons to transport between two EGPs across the SSPCM matrix. At the same time, relatively high MWCNT content led to aggregation in the SSPCM matrix (Figure 8(b2,c2)), and fewer MWCNTs adhered to the surface or edge of EPGs (Figure 8(b3,c3)). As a result, the thermal conductive network could not be constructed, and the interface thermal resistance was increased (Figure $8(b 1, c 1)$ ). Therefore, the synergistic effect between EGPs and MWCNT disappeared. The composites exhibited an additional property of two separated fillers. Thus, when the EGP/MWCNT ratio was 8:2, the composite exhibited the best thermal conductivity enhancement of SSPCM.
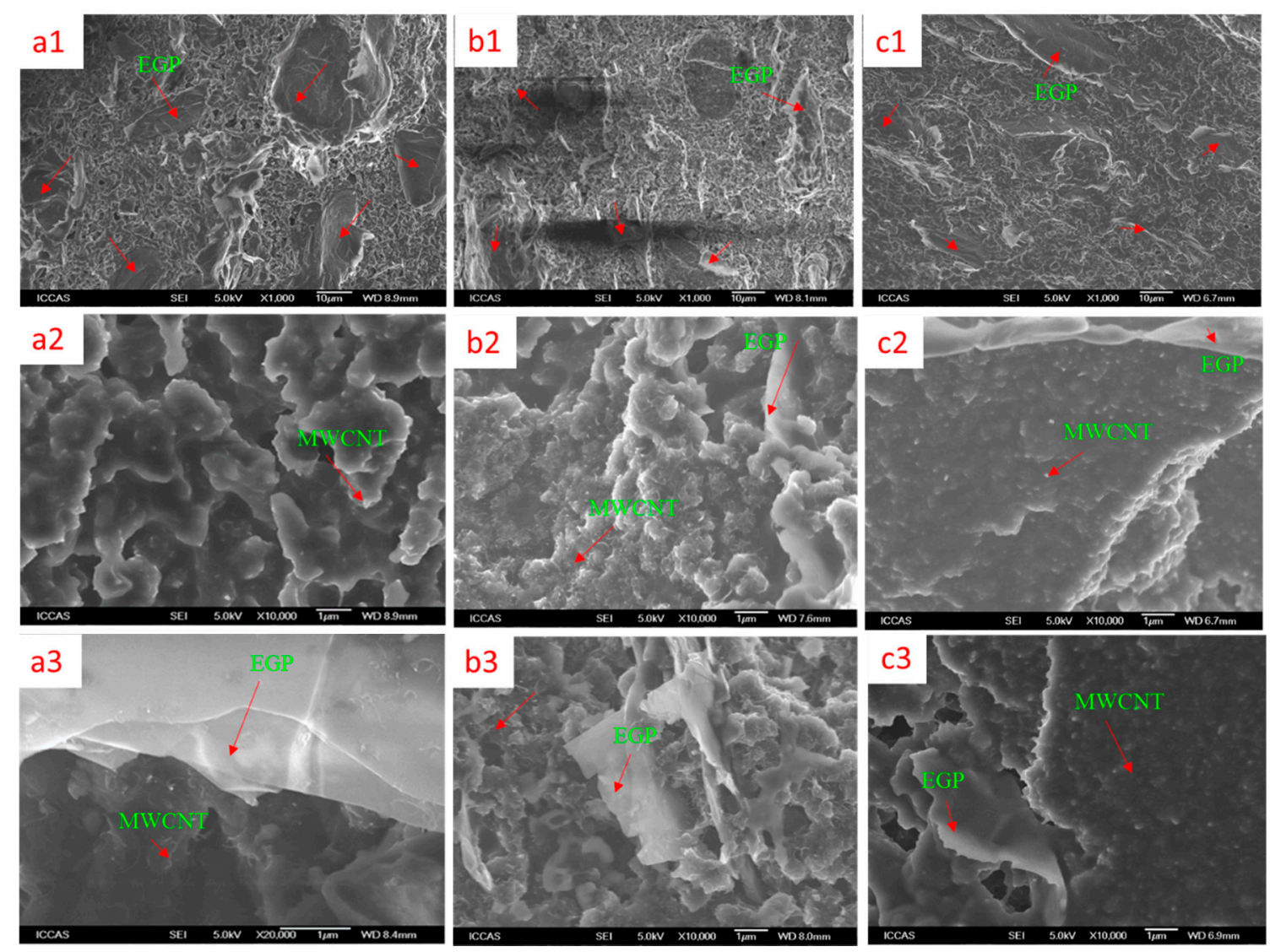

Figure 8. SEM photographs of PCM-EGP ${ }_{8} \mathrm{MWCNT}_{2}$ ((a1) $(1000 \times) ;(\mathbf{a 2})(10,000 \times)$; (a3) (20, 000×)); PCM-EGP $_{5} \mathrm{MWCNT}_{5}((\mathbf{b} 1)(1000 \times),(\mathbf{b} 2)(10,000 \times),(\mathbf{b} 3)(10,000 \times))$; and PCM-EGP ${ }_{3} \mathrm{MWCNT}_{7}((\mathbf{c} \mathbf{1})$ $(1000 \times),($ c2) $(10,000 \times),(c 3)(10,000 \times))$.

The synergistic mechanism of the thermal conductivity enhancement of SSPCM by hybrid $\mathrm{EGP}_{\mathrm{x}}-\mathrm{MWCNT}_{10-\mathrm{x}}$ filler is schematically illustrated in Figure 9. At appropriate EGP/MWCNT ratios, 7:3-9:1 in this paper, both EGPs and MWCNTs were dispersed well in the SSPCM matrix. Good dispersion of relatively high content EGPs created a high volume concentration of EGPs and a short distance between EGPs. At the same time, good dispersion of long and flexible MWCNTs made them more likely to connect EGPs and construct bridging structures (red lines in Figure 9). Now, the highly thermally-conductive network was constructed, and it is possible for phonons to transport along the highly-conductive backbone and bypass the low conductive matrix [38]. Furthermore, strong 
interaction between EGPs and MWCNTs decreased the interface thermal resistance. Therefore, the synergistic effect was observed. In contrast, at lower EGP/MWCNT ratios, EGPs were dispersed well, while the relatively high content of MWCNTs were easy to aggregate. The low content of EGPs made them separate farther apart. In this case, it is difficult for MWCNTs to connect to them. The aggregation of MWCNTs worsened in the situation. Therefore, only local heat transfer channels were formed, as show in Figure 9b, and the thermal conductivity of the hybrid-filled SSPCM was the same as the addition of the two individual fillers.
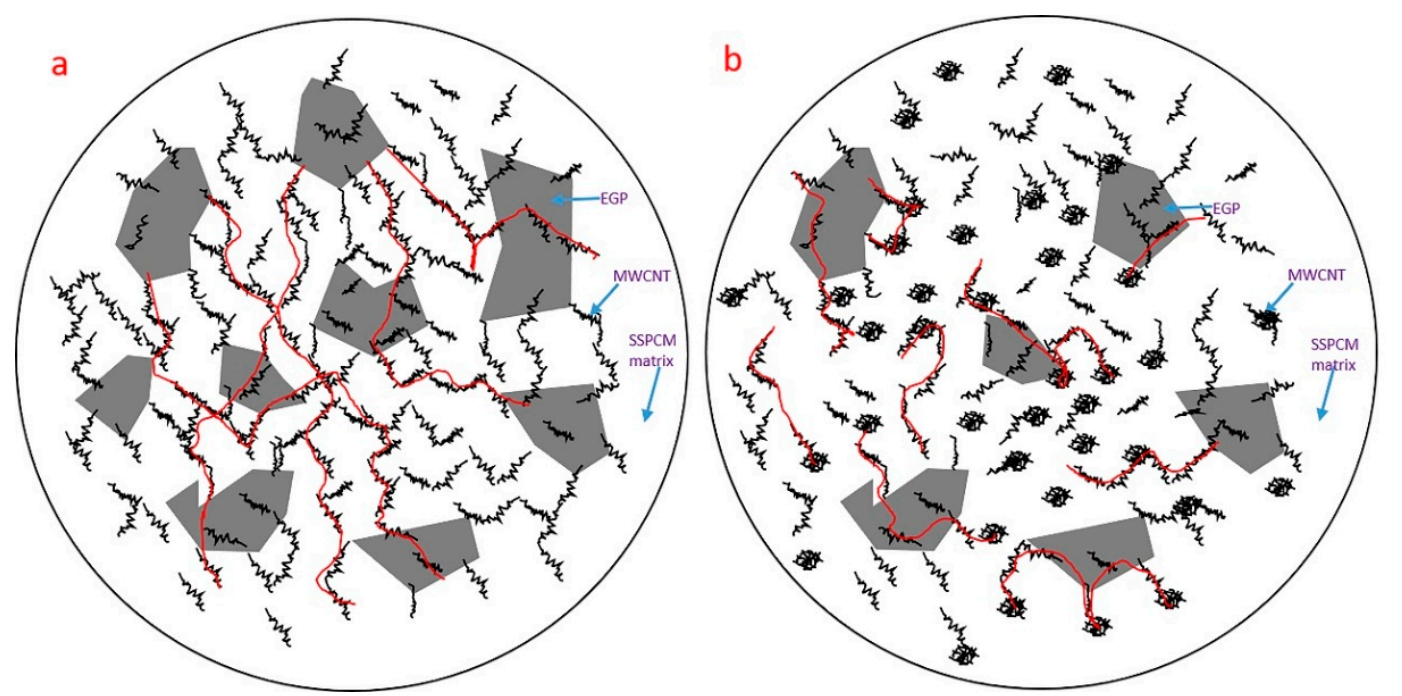

Figure 9. Schematic illustration of the EGP-MWCNT network in the SSPCM matrix: (a) the EGP/MWCNT ratio greater than 5:5; and (b) the EGP/MWCNT ratio less than 5:5.

\section{Conclusions}

In this study, the effect of EGP, MWCNT, and their hybrid filler on the thermal conductivity of SSPCM was investigated. In order to achieve good dispersion, pretreatment by high-speed shear and sonication of fillers were carried out before they were blended with SSPCM. The thermal conductivity of the SSPCM increased with the EGP or MWCNT content, and EGP showed a greater thermal conductivity improvement than MWCNT. At about $9 \mathrm{wt} \%$, EGP and MWCNT increased the thermal conductivity of SSPCM by $246 \%$ and $159 \%$, respectively, compared to that of pure SSPCM. Incorporation of 1D flexible MWCNT and 2D EGP together, both with high thermal conductivity and high aspect ratios, gave rise to a bridging structure between them, which helped the formation of a thermal conduction network, with decreased interface thermal resistance. Therefore, a synergistic effect was exhibited. When the EGP/MWCNT ratio was $8: 2$, the thermal conductivity reached $0.674 \mathrm{~W} / \mathrm{mK}$, $288 \%$ that of the SSPCM and about $117 \%$ that of PCM-10EGP.

Acknowledgments: This work was financially supported by National Key Research and Development Program of China (no. 2016YFB0901405)

Author Contributions: Rui Yang conceived and designed the experiments; Zhang-Peng Liu performed the experiments and wrote the paper.

Conflicts of Interest: The authors declare no conflict of interest.

\section{References}

1. Zhou, D.; Zhao, C.Y.; Tian, Y. Review on thermal energy storage with phase change materials (pcms) in building applications. Appl. Energy 2012, 92, 593-605. [CrossRef]

2. Farid, M.M.; Khudhair, A.M.; Razack, S.A.K.; Al-Hallaj, S. A review on phase change energy storage: Materials and applications. Energy Convers. Manag. 2004, 45, 1597-1615. [CrossRef] 
3. Jana, S.; Salehi-Khojin, A.; Zhong, W.-H. Enhancement of fluid thermal conductivity by the addition of single and hybrid nano-additives. Thermochim. Acta 2007, 462, 45-55. [CrossRef]

4. Li, G.; Hwang, Y.; Radermacher, R. Review of cold storage materials for air conditioning application. Int. J. Refrig. 2012, 35, 2053-2077. [CrossRef]

5. Karaipekli, A.; Biçer, A.; Sarı, A.; Tyagi, V.V. Thermal characteristics of expanded perlite/paraffin composite phase change material with enhanced thermal conductivity using carbon nanotubes. Energy Convers. Manag. 2017, 134, 373-381. [CrossRef]

6. Wu, S.; Zhu, D.; Zhang, X.; Huang, J. Preparation and melting/freezing characteristics of cu/paraffin nanofluid as phase-change material (pcm). Energy Fuel 2010, 24, 1894-1898. [CrossRef]

7. Zeng, J.-L.; Zhu, F.-R.; Yu, S.-B.; Zhu, L.; Cao, Z.; Sun, L.-X.; Deng, G.-R.; Yan, W.-P.; Zhang, L. Effects of copper nanowires on the properties of an organic phase change material. Sol. Energy Mater. Sol. Cell 2012, 105, 174-178. [CrossRef]

8. Xiao, X.; Zhang, P.; Li, M. Preparation and thermal characterization of paraffin/metal foam composite phase change material. Appl. Energy 2013, 112, 1357-1366. [CrossRef]

9. Chintakrinda, K.; Weinstein, R.D.; Fleischer, A.S. A direct comparison of three different material enhancement methods on the transient thermal response of paraffin phase change material exposed to high heat fluxes. Int. J. Therm. Sci. 2011, 50, 1639-1647. [CrossRef]

10. Wang, J.; Xie, H.; Li, Y.; Xin, Z. Pw based phase change nanocomposites containing $\gamma-\mathrm{Al}_{2} \mathrm{O}_{3}$. J. Therm. Anal. Calorim. 2010, 102, 709-713. [CrossRef]

11. Ho, C.J.; Gao, J.Y. Preparation and thermophysical properties of nanoparticle-in-paraffin emulsion as phase change material. Int. Commun. Heat Mass 2009, 36, 467-470. [CrossRef]

12. Jesumathy, S.; Udayakumar, M.; Suresh, S. Experimental study of enhanced heat transfer by addition of cuo nanoparticle. Heat Mass Transf. 2011, 48, 965-978. [CrossRef]

13. Fan, L.; Khodadadi, J.M. An experimental investigation of enhanced thermal conductivity and expedited unidirectional freezing of cyclohexane-based nanoparticle suspensions utilized as nano-enhanced phase change materials (nepcm). Int. J. Therm. Sci. 2012, 62, 120-126. [CrossRef]

14. Wang, J.; Xie, H.; Xin, Z.; Li, Y.; Chen, L. Enhancing thermal conductivity of palmitic acid based phase change materials with carbon nanotubes as fillers. Sol. Energy 2010, 84, 339-344. [CrossRef]

15. Shi, J.-N.; Ger, M.-D.; Liu, Y.-M.; Fan, Y.-C.; Wen, N.-T.; Lin, C.-K.; Pu, N.-W. Improving the thermal conductivity and shape-stabilization of phase change materials using nanographite additives. Carbon 2013, 51, 365-372. [CrossRef]

16. Zhang, Q.; Wang, H.; Ling, Z.; Fang, X.; Zhang, Z. Rt100/expand graphite composite phase change material with excellent structure stability, photo-thermal performance and good thermal reliability. Sol. Energy Mater. Sol. Cell 2015, 140, 158-166. [CrossRef]

17. Kim, S.; Drzal, L.T. High latent heat storage and high thermal conductive phase change materials using exfoliated graphite nanoplatelets. Sol. Energy Mater. Sol. Cell 2009, 93, 136-142. [CrossRef]

18. Sarı, A.; Karaipekli, A. Thermal conductivity and latent heat thermal energy storage characteristics of paraffin/expanded graphite composite as phase change material. Appl. Therm. Eng. 2007, 27, 1271-1277. [CrossRef]

19. Xia, L.; Zhang, P.; Wang, R. Preparation and thermal characterization of expanded graphite/paraffin composite phase change material. Carbon 2010, 48, 2538-2548. [CrossRef]

20. Py, X.; Olives, R.; Mauran, S. Paraffin/porous-graphite-matrix composite as a high and constant power thermal storage material. Int. J. Heat Mass Transf. 2001, 44, 2727-2737. [CrossRef]

21. Mills, A.; Farid, M.; Selman, J.; Al-Hallaj, S. Thermal conductivity enhancement of phase change materials using a graphite matrix. Appl. Therm. Eng. 2006, 26, 1652-1661. [CrossRef]

22. Ji, H.; Sellan, D.P.; Pettes, M.T.; Kong, X.; Ji, J.; Shi, L.; Ruoff, R.S. Enhanced thermal conductivity of phase change materials with ultrathin-graphite foams for thermal energy storage. Energy Environ. Sci. 2014, 7, 1185-1192. [CrossRef]

23. Wang, J.; Xie, H.; Xin, Z. Thermal properties of paraffin based composites containing multi-walled carbon nanotubes. Thermochim. Acta 2009, 488, 39-42. [CrossRef]

24. Fan, L.-W.; Fang, X.; Wang, X.; Zeng, Y.; Xiao, Y.-Q.; Yu, Z.-T.; Xu, X.; Hu, Y.-C.; Cen, K.-F. Effects of various carbon nanofillers on the thermal conductivity and energy storage properties of paraffin-based nanocomposite phase change materials. Appl. Energy 2013, 110, 163-172. [CrossRef] 
25. Mehrali, M.; Latibari, S.T.; Mehrali, M.; Metselaar, H.S.C.; Silakhori, M. Shape-stabilized phase change materials with high thermal conductivity based on paraffin/graphene oxide composite. Energy Convers. Manag. 2013, 67, 275-282. [CrossRef]

26. Li, M. A nano-graphite/paraffin phase change material with high thermal conductivity. Appl. Energy 2013, 106, 25-30. [CrossRef]

27. Fang, X.; Fan, L.-W.; Ding, Q.; Wang, X.; Yao, X.-L.; Hou, J.-F.; Yu, Z.-T.; Cheng, G.-H.; Hu, Y.-C.; Cen, K.-F. Increased thermal conductivity of eicosane-based composite phase change materials in the presence of graphene nanoplatelets. Energy Fuel 2013, 27, 4041-4047. [CrossRef]

28. Sar1, A. Form-stable paraffin/high density polyethylene composites as solid-liquid phase change material for thermal energy storage: Preparation and thermal properties. Energy Convers. Manag. 2004, 45, 2033-2042. [CrossRef]

29. Wang, Y.; Wang, S.Y.; Wang, J.P.; Yang, R. Preparation, stability and mechanical property of shape-stabilized phase change materials. Energy Build. 2014, 77, 11-16. [CrossRef]

30. Wang, J.P.; Wang, Y.; Yang, R. Flame retardance property of shape-stabilized phase change materials. Sol. Energy Mater. Sol. Cell 2015, 140, 439-445. [CrossRef]

31. AlMaadeed, M.; Labidi, S.; Krupa, I.; Karkri, M. Effect of expanded graphite on the phase change materials of high density polyethylene/wax blends. Thermochim. Acta 2015, 600, 35-44. [CrossRef]

32. Sobolciak, P.; Karkri, M.; Al-Maadeed, M.A.; Krupa, I. Thermal characterization of phase change materials based on linear low-density polyethylene, paraffin wax and expanded graphite. Renew. Energy 2016, 88, 372-382. [CrossRef]

33. Cheng, W.-L.; Zhang, R.-M.; Xie, K.; Liu, N.; Wang, J. Heat conduction enhanced shape-stabilized paraffin/hdpe composite pcms by graphite addition: Preparation and thermal properties. Sol. Energy Mater. Sol. Cell 2010, 94, 1636-1642. [CrossRef]

34. Xiao, M.; Feng, B.; Gong, K. Preparation and performance of shape stabilized phase change thermal storage materials with high thermal conductivity. Energy Convers. Manag. 2002, 43, 103-108. [CrossRef]

35. Zhang, Y.; Ding, J.; Wang, X.; Yang, R.; Lin, K. Influence of additives on thermal conductivity of shape-stabilized phase change material. Sol. Energy Mater. Sol. Cell 2006, 90, 1692-1702. [CrossRef]

36. Yang, D.J.; Wang, S.G.; Zhang, Q. Thermal and electrical transport in multi-walled carbon nanotubes. Phys. Lett. A 2004, 329, 207-213. [CrossRef]

37. Kim, P.; Shi, L.; Majumdar, A.; McEuen, P.L. Thermal transport measurements of individual multiwalled nanotubes. Phys. Rev. Lett. 2001, 87, 215502. [CrossRef] [PubMed]

38. Yu, A.P.; Ramesh, P.; Sun, X.B.; Bekyarova, E.; Itkis, M.E.; Haddon, R.C. Enhanced thermal conductivity in a hybrid graphite nanoplatelet-carbon nanotube filler for epoxy composites. Adv. Mater. 2008, 20, 4740-4744. [CrossRef]

(C) 2017 by the authors. Licensee MDPI, Basel, Switzerland. This article is an open access article distributed under the terms and conditions of the Creative Commons Attribution (CC BY) license (http://creativecommons.org/licenses/by/4.0/). 